Periodica Polytechnica Civil Engineering, 63(2), pp. 577-592, 2019

\title{
Design of Transverse Stiffeners in Plate Girders with Corrugated Web
}

\author{
Witold Basiński1* \\ ${ }^{1}$ Faculty of Civil Engineering, \\ Silesian University of Technology \\ Akademicka 5, 44-100 Gliwice, Poland \\ *Corresponding author, e-mail: witold.basinski@polsı.pl
}

Received: 30 January 2019, Accepted: 20 March 2019, Published online: 30 April 2019

\begin{abstract}
This study reports investigations into the effect of relative flexural stiffness of intermediate stiffeners $y$ on the failure zone location in the corrugated web. The study also aimed at obtaining stiffness criterion for intermediate stiffeners that depends on the magnitude of the plate geometry parameter $a$. To achieve the goals of the study, experimental investigations were conducted into load displacement paths of four exemplary SIN girders. They were simply supported girders, made to full scale, and composed of pre-assembled units. The phenomena occurring in the experiment were represented using the Finite Element Method. For FEM numerical analysis of girders with intermediate stiffeners, models with the web height of 1000, 1250 and $1500 \mathrm{~mm}$, made from 2; 2.5 and 3 mm thick corrugated sheet metal were used. Due to the analysis of 52 girder numerical models, it was possible to propose the stiffness criterion of intermediate stiffeners. The criterion was based on the assessment of shear buckling strength of the corrugated web. Using the regression method, dimensionless coefficients of the stiffener stiffness $k_{s}$ dependent on the optimum stiffness $y$ were determined. Based on estimated coefficients of the stiffener stiffness $k_{s^{\prime}}$, the absolute minimum stiffness of intermediate stiffeners $l_{\text {smin }}$ used in corrugated web plate girders was calculated. It was demonstrated that the use of an intermediate stiffener, the stiffness of which is greater than $I_{\text {smin }}$, additionally leads to a change in the location of the site of the web shear buckling.
\end{abstract}

\section{Keywords}

sine wave corrugated web girders, intermediate stiffener, dimensionless stiffness coefficient, zone of failure of the corrugated web, Finite Element Method

\section{Introduction}

While designing I-shaped plate girders, in which a bending moment is a major action, it is necessary to o utilise webs with slender walls so that girder weight is reduced. However, when slenderness of the web is too high, local and global web stability failures occur quickly. The solution to the problem turned out to be an idea, developed in the 1930s, to use profiled sheet metal for plate girder webs. Sheet metal folds perpendicular to chords were to act as web stiffening, and to increase buckling stress so that slender-walled webs could be used.

The most commonly used folds are trapezoidal or sinusoidal in shape. For enclosed buildings, corrugated web girders with sinusoidal web profile are 2.0; 2.5 and $3.0 \mathrm{~mm}$ thick and have the height ranging from 333 to $1500 \mathrm{~mm}$. The minimum guaranteed yield strength of corrugated web steel is $f_{y}=235 \mathrm{MPa}$.
With respect to plate girders with flat webs, when constructing box bridges [1] it was observed that the use of transverse stiffeners produces an increase in shear buckling stress and normal buckling stress of the web. Additionally, that also leads to increased normal stress in chords. The flexural stiffness of the stiffener was adopted as a criterion in dimensioning. It was done in such a way so that the axis of the web buckling surface was formed in the axis of rigid stiffener. Stiffeners were designed in accordance with the models based on the linear theory of stiffened plates. One of the first models dealing with stiffeners in the pre-buckling range was the solution developed by Timoshenko in 1915 [2]. Successive models included those presented by Moore [3], Rockey [4], and also Klöppel and Scheer [5]. The models, based on estimating the relative flexural stiffness of the stiffener $\gamma$, were dependent on the 
value of the plate geometry parameter $\alpha$. The quoted solutions, relying on buckling stress of elastic stability failure, were employed throughout the 20th century. Yet the first study on post-buckling behaviour of plate girders in railway bridges was presented by J. M. Wilson as early as in 1886. The solution is described in [6]. One of exemplary solutions for webs of plate girders under post buckling conditions is the model produced by Maquoi and Škaloud in 1981 [7, 8]. The solution resulted from comparison of a previous model developed by Škaloud with experimental results. Höglund [9] produced a number of models that described the effect of intermediate stiffeners on the magnitude of buckling stress. In 1999, the researcher published a study on behaviour of semirigid and rigid support stiffeners, and the effect produced by those on shear buckling stress.

In girders with corrugated web, intermediate transverse stiffeners are not used to increase shear buckling resistance of the corrugated web because sheet folds, perpendicular to chords, constitute the web stiffening. However, as shown in study [10], support stiffeners mounted at girder ends contribute to resistance increase. Additionally, they affect change in the web failure mode from global to interactive one. Then, intermediate stiffeners in existing girders with corrugated web take the form of end plate connections of individual pre-assembled units. They are used to avoid pressure, or to connect girder to secondary beams. Due to the above, based on investigations reported in [11], it was noted that when intermediate stiffener of the girder having the web height of $h_{w}=500 \mathrm{~mm}$ was made from $10 \mathrm{~mm}$ thick sheet, shear mode of the web instability always occurred at the intermediate stiffener joint. Next, in the author's studies [10-13], it was observed that for intermediate stiffener with increased stiffness taking the form of end plate connection of the girder pre-assembled units, the zone of the web shear instability shifted from the intermediate stiffener towards the support. Stiffness of intermediate stiffeners caused the relocation of the corrugated web failure zone.

This study reports investigations into the optimum stiffness of intermediate stiffeners $\gamma$ that are used in SIN girders. The aim of the study was to determine the stiffness criterion of intermediate stiffeners based on the assessment of shear buckling resistance of the corrugated web. For that purpose, load-displacement paths of four exemplary, simply supported SIN girders, made to natural scale and composed of pre-assembled units were analysed. Girders were designed in accordance with the code and guidelines $[14,15]$. The phenomena that occur in the experiment [16] were represented using the Finite Element Method [17].
FEM numerical analysis of girders with intermediate stiffeners was carried out using 52 models having the web height of 1000, 1250 and $1500 \mathrm{~mm}$. The models differed with respect to the value of the plate geometry parameter $\alpha$. Corrugated sheet of the web was 2; 2.5 and $3 \mathrm{~mm}$ in thickness. Failure modes of the corrugated web obtained from experimental and numerical tests were compared. Dimensionless coefficients of the stiffness of the stiffener $k_{s}$, dependent on the optimum stiffness $\gamma$, were determined. Based on estimated coefficients of the stiffener stiffness $k_{s}$, the absolute minimum stiffness of intermediate stiffeners $I_{\text {smin }}$, used in corrugated web plate girders was calculated. It was shown how the use of an intermediate stiffener with the absolute stiffness greater than $I_{\text {smin }}$ may additionally affect the location of the site of the web shear buckling.

\section{Transverse stiffeners in plate girders}

In plate girders with flat webs, transverse intermediate stiffeners are designed as open cross-section profiles, i.e. flat bars, T-bars and angles. Stiffeners are used both on one, and two sides of the flat web. As for thin-walled webs up to $6 \mathrm{~mm}$, intermediate stiffeners are assumed to be shifted with respect to one another.

When making calculations for intermediate stiffeners, the most frequently used loading diagram is that of twohinge rod supported on chords of plate girders, with the span equal to the web height. The transverse section area is most often assumed to be equivalent to cross section. It is formed of stiffeners made from steel members and interacting parts of the web that are selected arbitrarily.

The choice of the section of transverse stiffeners is made on the basis of identification of the optimal stiffness $\gamma$. The latter is a function of the type of load and the plate geometry parameter $\alpha$ (length-to-height ratio of the plate). Thus, the optimal stiffness $\gamma$ is expressed as the ratio of buckling stress in the plate of concern to Euler critical stress $\left(\sigma_{c r} / \sigma_{E}\right)$. In the literature, three types of the optimal stiffness are found, namely the first $\gamma_{\mathrm{I}}$, the second $\gamma_{\mathrm{II}}$ and the third type $\gamma_{\mathrm{III}}$.

The values of optimal stiffness for the stiffening of rectangular plates under shear were given, in tabular format, by Timoshenko in 1915 [2] (Table 1).

In 1942, Moore [3] proposed an empirically obtained formula for calculating optimal stiffness, which was also dependent on the plate geometry parameter $\alpha$ :

$\gamma=\frac{14}{\alpha^{3}}$. 




a)

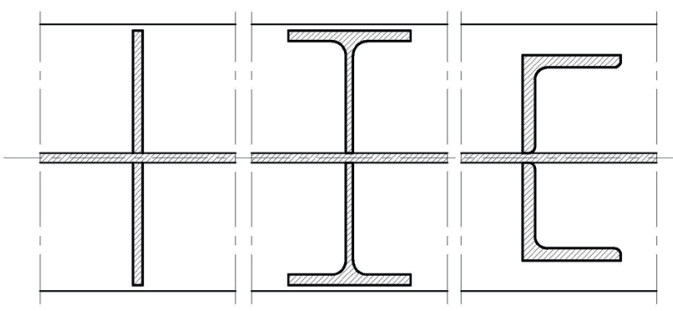

b)

Fig. 1 Cross-sections of intermediate stiffeners in flat plate girders

Table 1 Optimal stiffness of the transverse stiffeners acc [2]

\begin{tabular}{lccccccc}
\hline \multirow{2}{*}{$\begin{array}{l}\text { Number of } \\
\text { stiffeners }\end{array}$} & \multicolumn{7}{c}{ Parameter of geometry of the plate $\alpha$} \\
\hline 1 & 1.0 & 1.2 & 1.25 & 1.5 & 2.0 & 2.5 & 3.0 \\
\hline 2 & - & 22.6 & - & 10.7 & 3.53 & 1.37 & 0.64 \\
\hline
\end{tabular}

In 1956, after conducting experimental investigations, Rockey [4] put forward a proposal that concerned determining the optimum stiffness for coaxial stiffeners and for eccentric stiffeners:

$\gamma=\left\{\begin{array}{lll}\frac{28}{\alpha}-20 \alpha & \text { for } & \text { coaxial stiffeners } \\ \frac{21.5}{\alpha^{2}}-7.5 & \text { for } & \text { eccentric stiffeners }\end{array}\right.$.

In another solution that dealt with the web reinforced with transverse stiffeners, optimal stiffness proposed by Klöppel and Scheer [5] was expressed as follows:

$$
\gamma=\frac{5.4}{\alpha}\left(\frac{2}{\alpha}+\frac{2.5}{\alpha^{2}}-\frac{1}{\alpha^{3}}-1\right) \quad \text { but } \quad 0.5 \leq \alpha \leq 2 \text {. }
$$

In study [7], based on experimental investigations, Maqoui, Massonnet, Škaloud devised a formula employing non-linear stability of plates. They developed the method for determining the optimal stiffness of intermediate stiffeners for the webs in post-buckling behaviour acc. Eq. (4):

$$
\begin{aligned}
& \gamma_{o}=m_{M} \gamma, \\
& m_{M}=\left\{\begin{array}{lll}
1 & \text { for } & b / t \leq 75 \\
3 & \text { for } & b / t \geq 150
\end{array} .\right.
\end{aligned}
$$

where $b$ is the plate height, $t$ - the plate thickness.
A similar approach, based on non-linear stability of plates, was adopted by Škaloud in [8]. He showed that in post-buckling behaviour, stiffness of the intermediate stiffener $\gamma_{o}$ is sufficient if the optimal stiffness $\gamma$ determined for the pre-buckling state is increased three times by means of factor $m_{s}$.

$\gamma_{o}=m_{s} \gamma$

Design code and guidelines that are currently in force recommend that intermediate stiffeners should be dimensioned by establishing restrictions on their minimal absolute stiffness $I_{s}$. In the standard EN 1993-1-5 [14], the recommendations on minimal stiffness of intermediate stiffeners are expressed as follows.

$$
I_{s}=\left\{\begin{array}{lll}
\frac{1.5}{\alpha^{2}} b t^{3} & \text { for } & \alpha<\sqrt{2} \\
0.75 b t^{3} & \text { for } & \alpha \geq \sqrt{2}
\end{array} .\right.
$$

With respect to guidelines outlined by ECCS [18] and AASHTO [19], stiffness $I_{s}$ of intermediate stiffeners should satisfy condition:

$I_{s} \geq \xi \cdot I^{*}$,

where: $\xi=4$ for open section stiffeners, and $\xi=2$ for closed section stiffeners, additionally the magnitude of equivalent stiffness was given by Eq. (8):

$I^{*}=\left(2.5\left(\frac{1}{\alpha}\right)^{2} \cdot 2\right) a t^{3}$ but $I^{*} \geq \frac{a t^{3}}{2}$,

where $a$ is the distance between intermediate stiffeners.

In girders with corrugated web, intermediate stiffeners are only found in the form of end plate connections of individual pre-assembled units, or are used to connect girder to secondary beams.

\section{Experimental investigations}

Experimental investigations were conducted to determine optimal stiffness of intermediate stiffeners $\gamma$, and the effect produced by stiffness on the location of the failure zone in the corrugated web. Optimal stiffness $\gamma$ of intermediate stiffeners is dependent on the plate geometry parameter $\alpha$, i.e. ratio of span $a$ between stiffeners of the web plate to the web height $h_{w}$ (Fig. 2). That makes it necessary to conduct tests on a very large number of girders. Experimental investigations in this study were intended to be preliminary, consequently the number of girders was limited to four. Exemplary experimental girders differed in the value of parameter $\alpha$. 

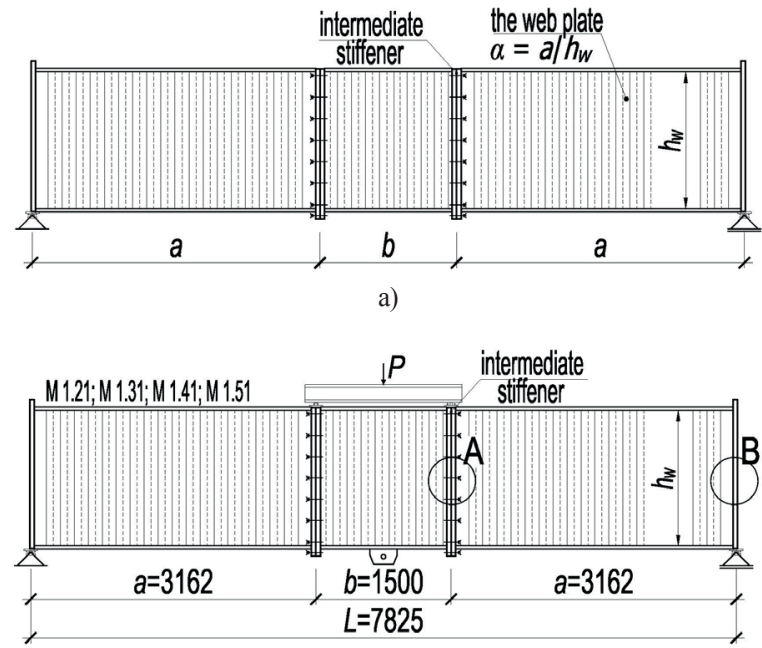

b)

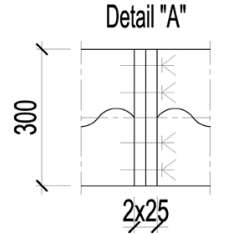

c)

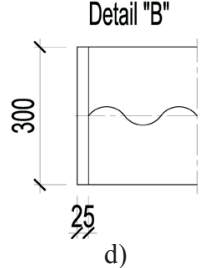

d)
Fig. 2 Corrugated web girders a) diagram of the ratio of the sides of the web plate; b) with intermediate stiffener; c), d) detail A, B

Table 2 Geometric dimensions of girders

\begin{tabular}{|c|c|c|c|c|c|c|}
\hline Girder & $\begin{array}{c}\text { Web } \\
h_{w} \times t_{w}\end{array}$ & $\begin{array}{c}\text { Web* } \\
\text { param. } \\
w / s / a_{w} \\
{[\mathrm{~m}]}\end{array}$ & $\begin{array}{c}\text { Flange } \\
b_{f} \times t_{f} \\
{[\mathrm{~mm}]}\end{array}$ & $\begin{array}{c}\mathrm{a} \\
{[\mathrm{mm}]}\end{array}$ & $\begin{array}{c}\mathrm{b} \\
{[\mathrm{mm}]}\end{array}$ & $\begin{array}{c}\mathrm{L} \\
{[\mathrm{mm}]}\end{array}$ \\
\hline M 1.21 & $1000 \times 2.5$ & $77.5 / 89 / 40$ & $300 \times 15$ & 3162 & 1500 & 7825 \\
\hline M 1.31 & $1000 \times 2.6$ & $77.5 / 89 / 40$ & $300 \times 20$ & 3162 & 1500 & 7825 \\
\hline M 1.41 & $1250 \times 2.0$ & $77.5 / 89 / 40$ & $300 \times 15$ & 3162 & 1500 & 7825 \\
\hline M 1.51 & $1500 \times 2.0$ & $77.5 / 89 / 40$ & $300 \times 15$ & 3162 & 1500 & 7825 \\
\hline
\end{tabular}

$* w$ denotes the length of the flange of the half-sine wave, $s-$ length of the arc of half-sine wave, $a_{w}$ - high of the sine wave

To determine shear buckling stress that is necessary to calculate optimal stiffness of intermediate stiffeners, load displacement paths of four exemplary SIN girders were examined. They were simply supported girders, made to full scale. The girders (M 1.21 WTB 1000, M 1.31 WTB 1000, M 1.41 WTA 1250, M 1.51 WTA 1500, Fig. 3a) were composed of pre-assembled units that had side lengths $a=3.16 \mathrm{~mm}$ (distance between intermediate and end stiffener) and $b=1.50 \mathrm{~m}$ (Table 2). In the tests, the following notations were used: M 1.21 - represents a subsequent girder model in the testing cycle. Letters WT denote a corrugated web girder (from Wellstegträger in German). A successive letter refers to the basic web thickness, i.e.: A $-2 \mathrm{~mm}, \mathrm{~B}-2.5 \mathrm{~mm}$. Successive numerals denote the web height $h_{w}$. Girder ends were made from $25 \mathrm{~mm}$ thick sheet metal (Fig. 2d, e), and girder chords - from $300 \times 15 \mathrm{~mm}$ universal plate. Girders were designed in accordance with standards and recommendations $[14,15]$.

Intermediate stiffeners (ST) were designed as end plate connections of pre-assembled units. They were friction grip connected using M24 bolts, class 10.9, the bearing capacity of which is greater than that of girders. Therefore, the bolts satisfied the requirements, from which it follows that rotation in the connection can be treated as a linear function of the rotational stiffness $S_{j}[12,21]$. Girder webs were fabricated, in accordance with the manufacturer's data, using $\mathrm{S}$ 235 steel, whereas chords were made from S 275 steel.

Steel frame (FR) was used to load the girders mounted onto the test stand (Fig. 3). The load, in the form of concentrated forces, was transferred by means of the actuator (1) via a dynamometer (2) onto the beam (3) and the girder (4) at the site of intermediate stiffeners (ST). Roller (5) and pin (6) supports were placed between the beam (3) and the girder (4). The girders were secured against lateral torsional buckling by diagonals braces (8) so that lateral displacements and the rotation of the compression chord could be prevented.

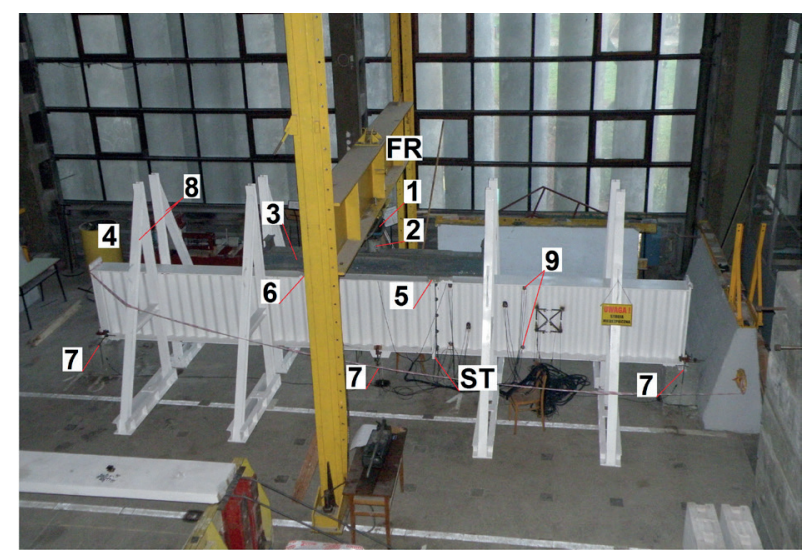

Fig. 3 Girder M1.21 with intermediate stiffener $300 \times 25 \mathrm{~mm} \times 2$ at the test stand

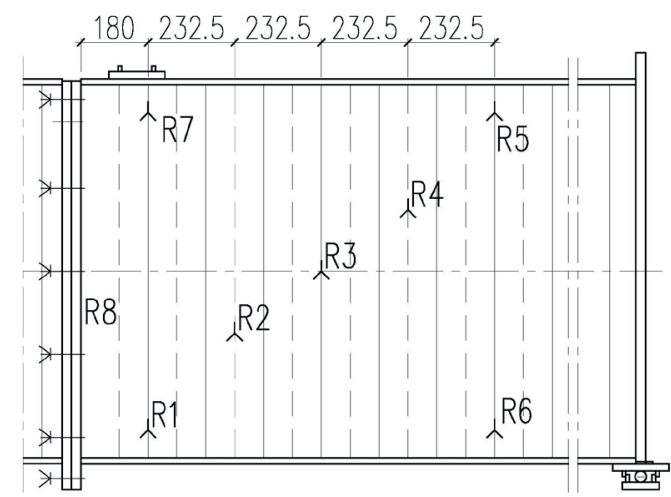

Fig. 4 Location of strain gauges on the girder web M 1.21 with intermediate stiffener $300 \times 25 \mathrm{~mm} \times 2$ 


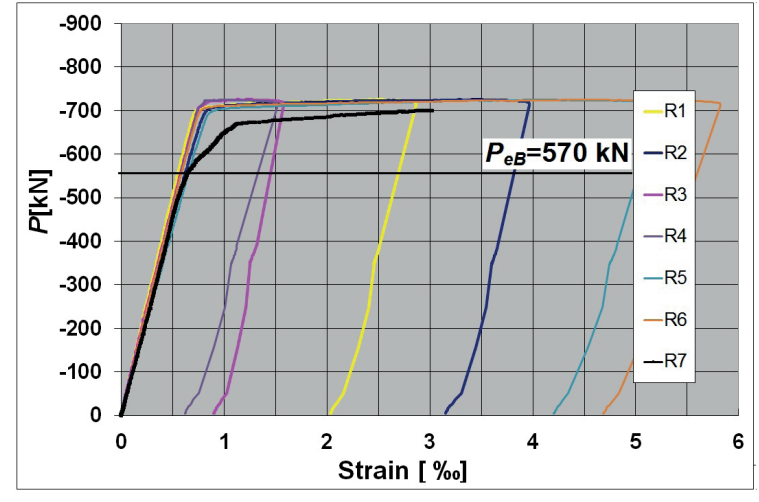

a)

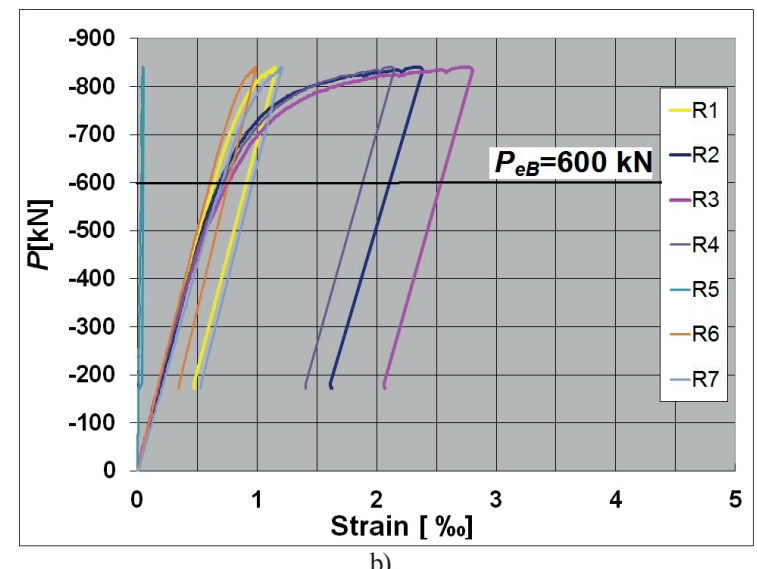

Fig. 5 Strains in the direction 600 relative to the axis of the web a) girder M 1.21; b) girder M 1. 41

a)

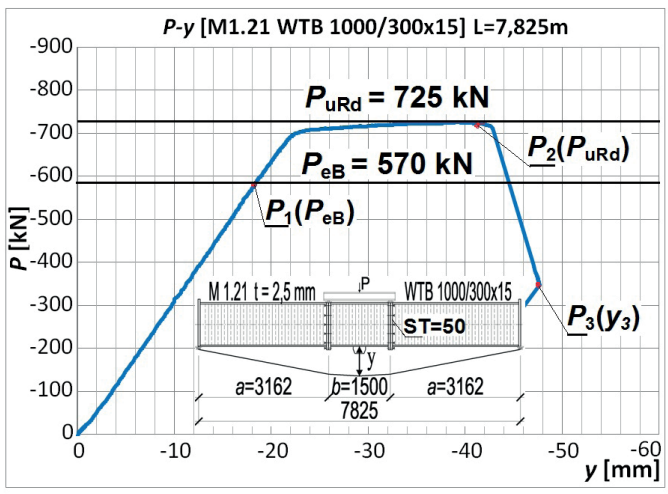

c)

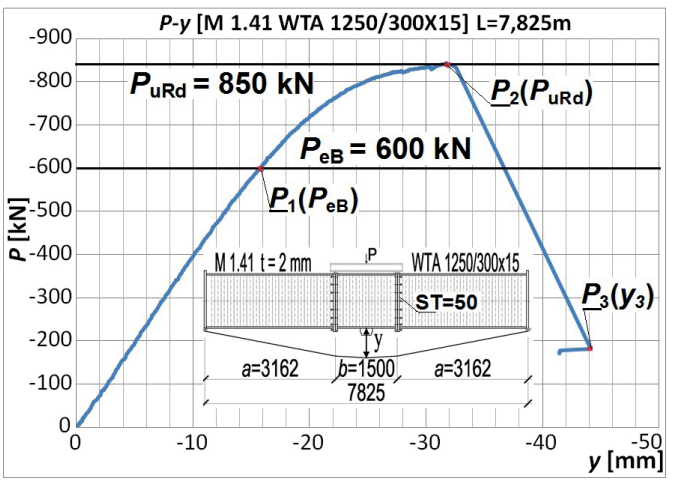

The following quantities were measured in the tests, the loading force $P$, the total deflections of the girder $y$, strain in the corrugated web and the settlement of supports. Inductive sensors (7) were employed to measure girder deflections. An array of strain gauges (9) in the form of strain rosettes is shown in Fig. 4. Also, strain in chords and intermediate stiffeners was controlled. The load on girders increased uniformly at loading rate of $20 \mathrm{kN} / \mathrm{min}$ until the web stability failure.

\subsection{Loads - displacements paths (LDPs) $P(y)$ of experimental girders}

The onset of the corrugated web instability was determined on the basis of the analysis of strain recorded by diagonal strain gauges glued onto the web in the rosette arrangement. It was assumed that the buckling stress $P_{e B}$ is found at the point that is the end of the linear range of strain-load relation. In addition, in all exemplary girders, the onset of the web instability occurred for the strain that was significantly lower than $1 \%$. The strain-load relation for girders M1.21 and M 1. 41 is shown in Fig. 5.

Based on the global displacement $y$ measured at the midspan of girders, load-displacement paths LDPs $P(y)$ were obtained for the girders of concern. In Fig. 6, LDPs $P(y)$ are shown for all tested girders with intermediate stiffeners $300 \times 25 \mathrm{~mm} \times 2$.

b)

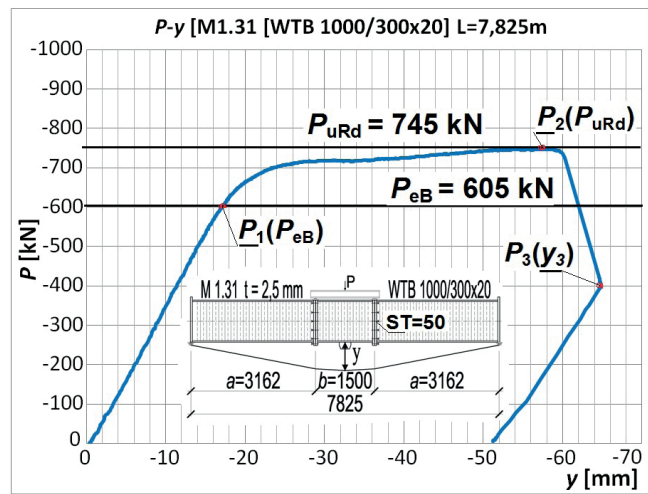

d)



Fig. 6 Load - displacements paths $P(y)$ of girders: a) M 1.21, b) M 1.31, c) M 1.41, d) M $1.51(300 \times 25 \mathrm{~mm} \times 2)$ 
In LDPs $P(y)$ presented in Fig. 6, characteristic coordinates $P_{1}\left(P_{e B}\right), P_{2}\left(P_{u R d}\right)$ and $P_{3}\left(y_{3}\right)$ were marked. Nonlinearity of the global displacement curve $P(y)$ started from coordinate $P_{1}\left(P_{e B}\right)$ following the occurrence of diagonal yield zones in the corrugated web. Nonlinearity coincided with the web instability onset indicated by the array of strain gauges.

Characteristic coordinates $P_{1}\left(P_{e B}\right), P_{2}\left(P_{u R d}\right), P_{3}\left(y_{3}\right)$, marked in Fig. 6, refer to the following:

$P_{1}\left(P_{e B}\right)$ - web stability failure signalled by the onset of a change in the web geometry corresponding to the first buckling load $P_{e B}$;

$P_{2}\left(P_{u R d}\right)$ - limit load from the condition of girder failure $P_{u R d}$ signalled by the end of tension field formation; $P_{3}\left(y_{3}\right)$ - unloading of girder.

In exemplary girders, the occurrence of the yield zones (coordinate $P_{1}\left(P_{e B}\right)$ ) clearly separates the quasi - linear part of displacements from non-linear displacements. That indicates the increment of displacements due to shear occurs with load increase and tension field propagation. A considerable influence of elastic - plastic displacements induced by transverse forces in the web on total girder displacements manifests itself in the range $P_{1}\left(P_{e B}\right)-P_{2}\left(P_{u R d}\right)$. For experimental girders, the spacing of intermediate stiffeners $a>h_{w}$ that gave the $\alpha$ parameter value greater than 1 resulted in the removal of the stiffening influence on the magnitude of the buckling load $P_{e B}$.

Table 3 lists the results of investigations into experimental girders. Column 6 shows limit load $P_{u R d}$ measured by force $P$, and Column 7 indicates buckling load $P_{e B}$ measured by force $P$.

\subsection{Failure modes of experimental girders with transverse stiffeners}

In the girders with transverse intermediate stiffeners, the web failure occurred in the zone under a constant transverse force. In each of the girders examined, intermediate stiffeners made from end-plate-connected sheets remained intact. Web failure was located at the distance of 1.9-2.2 m from the intermediate stiffener (ST). The process of corru- gated web failure started with the web local instability in the proximity of the tension bottom chord. Then, the tension field caused the occurrence of the yield zone (1) associated with the snap-through of the adjacent web waves (2) (interactive stability failure - I) (Fig. 7). The final stage involved the breaking of the girder chords (3). Because of the girder failure near the support, the bowing of the semirigid support stiffener occurred.

As regards investigations into similar girders acc. Fig. 8a [12] and 8b [11], made from WTA 500 profiles, the corrugated web failure was due to its local instability. Intermediate stiffener (ST) in girder B1 (Fig. 8a) was made as end-plate connection from two $30 \mathrm{~mm}$-thick sheets with an additional $20 \mathrm{~mm}$ separator sheet, which resulted in the shifting of the yield zone from the girder axis towards the support by approx. $1.7 \mathrm{~m}$. In girder B3, intermediate stiffener (Fig. 8b) was made form $10 \mathrm{~mm}$ sheet. That produced insufficient stiffening of the web and chords at the site of load application. Consequently, yield zone formed near intermediate stiffener.

In girders with stiffener that has low stiffness, a free deformation of the beam occurs. The web folds become stretched at the bottom and twisted at the top, that is $S_{1}>S_{2}$. (Fig. 9a). The most unfavourable ratio of the fold length to its thickness $S_{1} / t_{w}$ is found in the middle part of the girder. That leads to the situation when the most disadvantageous relation of the force from the tension field $V_{z y}$ to the wall limit slenderness, at which the web instability occurs, takes place in the middle of the girder, not far from the tension chord. As a result, the onset of the web instability comes in the flat part of the fold in the middle of the girder (Fig. 9a). The local exceedance of shear yield strength can also occur near the concentrated load under the tension chord. Enhancement of the flexural stiffness of intermediate stiffeners used in corrugated web girders results in increased stiffness of the web $E_{w} I_{w}$ and chords $E_{f} I_{f}$ (Fig. 9b). Consequently, the folds near the stiffener deform less than those located further away from it. Then, the most disadvantageous ratio $S_{1} / t_{w}$ shifts away from the intermediate stiffener, and the onset of the web instability

Table 3 Experimental results of girders

\begin{tabular}{lcccccc}
\hline Girder & Web $h_{w} \times t_{w}$ & Span $a[\mathrm{~m}]$ & $\alpha=a / h_{w}$ & Inter. stiffener mm $]$ & Limit load $P_{u, R d}[\mathrm{kN}]$ & First buckling load $P_{e B}[\mathrm{kN}]$ \\
1 & 2 & 3 & 4 & 3.2 & $300 \times 25 \times 2$ & 6 \\
\hline M 1.21 & $1000 \times 2.5$ & 3.16 & 3.2 & $300 \times 25 \times 2$ & 725 \\
M 1.31 & $1000 \times 2.6$ & 3.16 & 2.5 & $300 \times 25 \times 2$ & 745 & 850 \\
M 1.41 & $1250 \times 2.0$ & 3.16 & 2.1 & $300 \times 25 \times 2$ & 605 \\
M 1.51 & $1500 \times 2.0$ & 3.16 & 600 & 600 \\
\hline
\end{tabular}




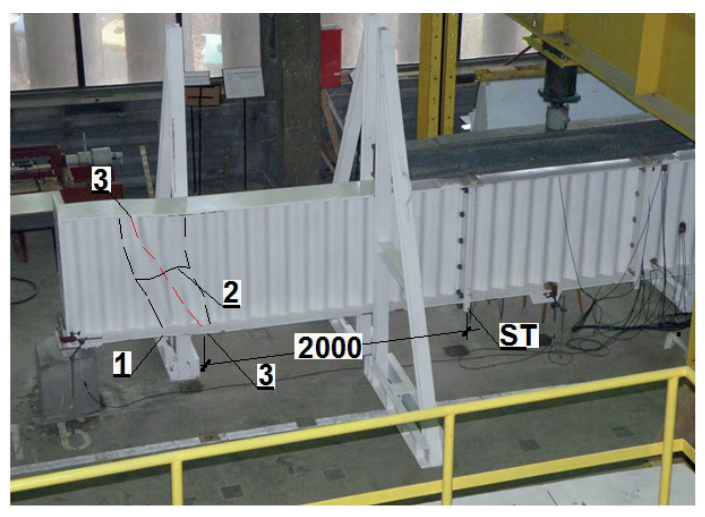

a)

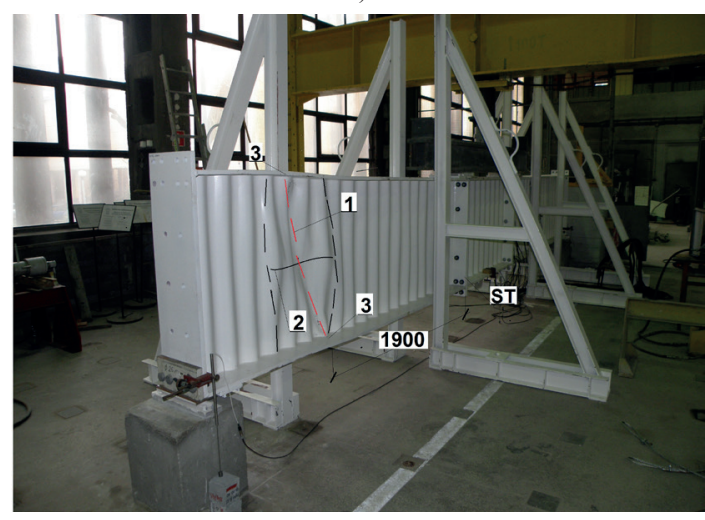

b)

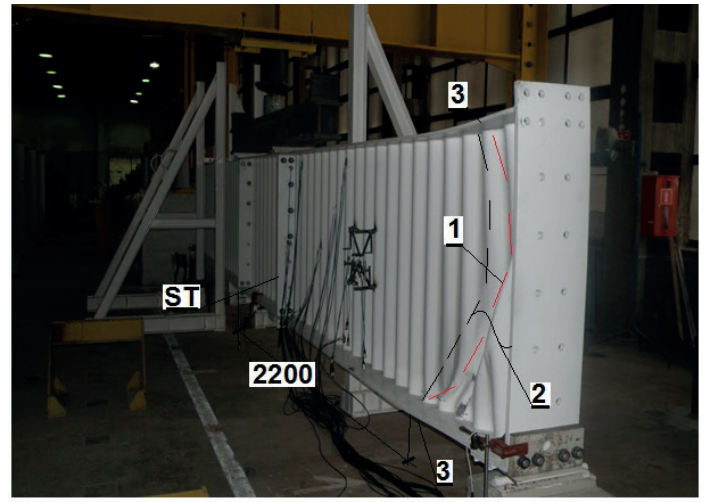

c)

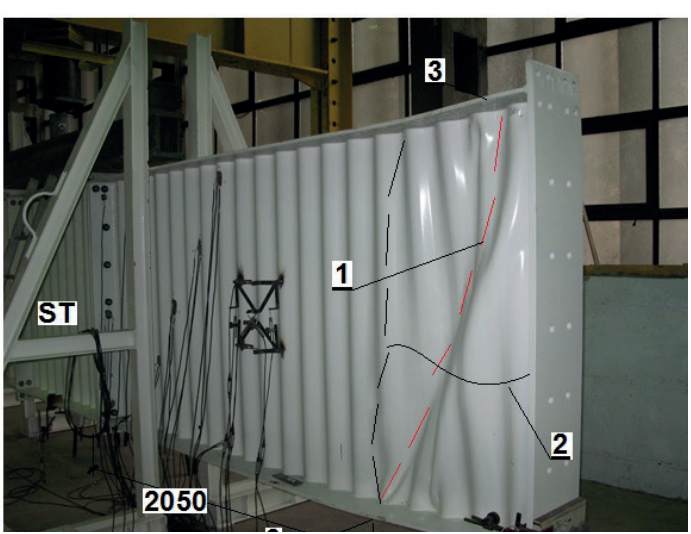

d)

Fig. 7 Failure modes of corrugated web girder: a) M 1.21, b) M 1.31 , c) M 1.41, d) M $151(300 \times 25 \mathrm{~mm} \times 2)$

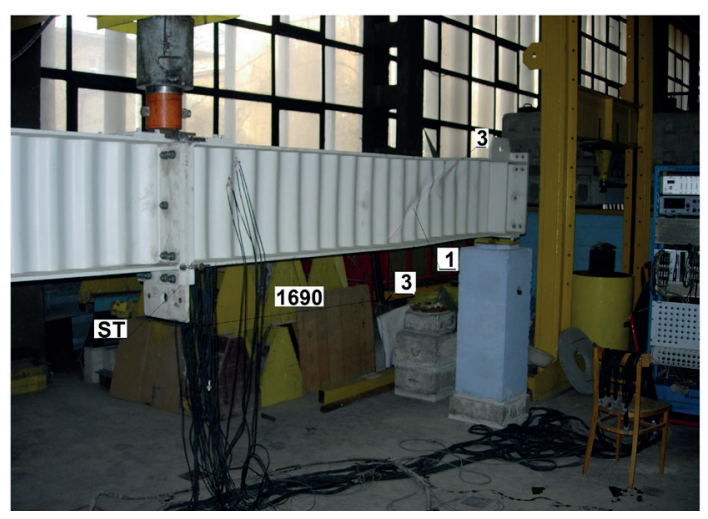

a)

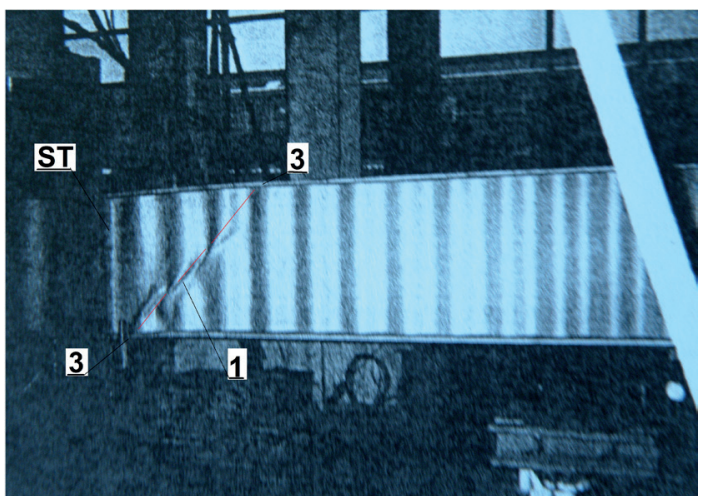

b)

Fig. 8 Failure modes of corrugated web girders: a)

B1 $(300 \times 30 \mathrm{~mm} \times 2+300 \times 20 \mathrm{~mm})[12]$; b) B-3 $(250 \times 10 \mathrm{~mm})[11]$

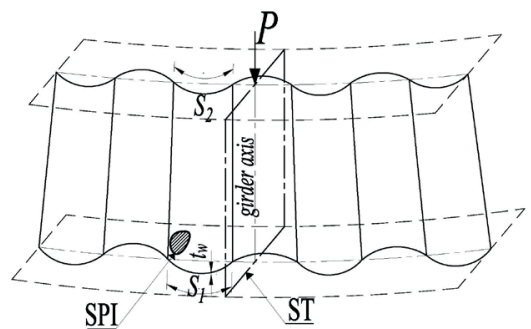

a)



b)

Fig. 9 The initial point of instability in corrugated web girders: a) with semirigid transverse stiffener b) with rigid transverse stiffener

moves towards the support. The relocation of the yield zone towards the support is mostly affected by the stiffness of the intermediate stiffener, and also by the girder self-weight that minimally increases the shear force. 
Table 4 Material properties

\begin{tabular}{|c|c|c|c|c|c|}
\hline Girder & $\begin{array}{c}\bar{f}_{y} \\
{[\mathrm{MPa}]}\end{array}$ & $\begin{array}{c}\bar{f}_{u} \\
{[\mathrm{MPa}]}\end{array}$ & $\begin{array}{c}\text { Percentage } \\
\text { total } \\
\text { elongation } \\
\text { at maximum } \\
\text { force }\left(F_{m}\right) \\
{[\%]}\end{array}$ & $\begin{array}{c}\text { Percentage } \\
\text { total } \\
\text { elongation } \\
\text { at fracture } \\
{[\%]}\end{array}$ & $\begin{array}{c}E \\
{[\mathrm{GPa}]}\end{array}$ \\
\hline \multicolumn{6}{|c|}{ web } \\
\hline M 1.21 & 275.9 & 416.0 & 15.4 & 20.7 & \\
\hline M 1.31 & 260.4 & 403.0 & 16.1 & 20.8 & \\
\hline M 1.41 & 317.8 & 434.3 & 16.8 & 21.6 & \\
\hline M 1.51 & 247.2 & 375.5 & 16.9 & 23.0 & \\
\hline \multicolumn{6}{|c|}{ flange } \\
\hline M 1.21 & 303.4 & 485.5 & 22.6 & 29.4 & 213 \\
\hline M 1.31 & 298.9 & 435.7 & 24.8 & 32.2 & 205 \\
\hline M 1.41 & 281.2 & 443.9 & 23.1 & 30.7 & 202 \\
\hline M 1.51 & 291.1 & 451.8 & 21.9 & 28.8 & 208 \\
\hline
\end{tabular}

\subsection{Materials testing of the steel used in experimental girders}

To obtain the materials parameters necessary to conduct FEM analysis, strength tests were performed acc. EN [22] on steel used in the fabrication of experimental girders. Test samples were collected from chords and corrugated web. For chords, yield strength tests were conducted on three randomly collected samples, whereas for the web, six samples were taken from each girder. Table 4 summarises the results of materials tests of experimental girders [23].

Due to substantial differences in yield strength of the web steel obtained from the tests, in FEM analysis, the same materials parameters were adopted for all numerical models. They were as follows: the web yield strength $f_{y}=281 \mathrm{MPa}$, tensile strength $f_{u}=375.5 \mathrm{MPa}$ and modulus of elasticity $E=210 \mathrm{GPa}$. For the chords: yield strength $f_{y}=306.7 \mathrm{MPa}$, tensile strength $f_{u}=449.3 \mathrm{MPa}$ and modulus of elasticity $E=203 \mathrm{GPa}$. The parameters were adopted on the basis of materials tests obtained for girder M 2.52 acc. [23]. Materials parameters used in the numerical analysis are very close to yield strength of girders M 1.21 and M 1.31.

\section{Numerical tests}

Numerical analysis of [17] corrugated web girders focused on finding the stiffness criterion of intermediate stiffeners that is dependent on the magnitude of plate geometry parameter $\alpha$. Additionally, the impact of absolute stiffness $I_{s}$ of intermediate stiffeners on the location of the corrugated web failure zone was examined. FEM analysis was carried out for 52 numerical models subdivided into two groups. The first group was used to establish the stiffness criterion of intermediate stiffeners. In the analysis, the geometry of girders in Fig. 3 was represented, and the span size $a$ was changed so that an appropriate magnitude of parameter $\alpha=a / h_{w}$ was obtained, namely that it should range from 0.6 (assumed $a_{\text {min }}=4^{*}$ wave length $=620$, hence $\alpha_{\text {min }}=a_{\text {min }} / h_{\text {wmin }}=620 / 1000=0.6$ ) to 2.1 (Fig. 10a and Table 4). The maximum value of parameter $\alpha=2.1$ was adopted, so that not to exceed the largest length of the girder span $a=3.16 \mathrm{~m}$ from the experimental investigations (for the girder with $h_{w}=1500 \mathrm{~mm}$ ). As all the end plate connections used in experimental tests were rigid, in the first group of numerical models, intermediate stiffeners were modelled as metal plates sheets, $50 \mathrm{~mm}$ in thickness, i.e. in the way corresponding to the thickness of sheet connections from experimental investigations.

The other group included 16 numerical models that were put to analysis. The geometry of girders shown in Fig. 3 was mapped, and the thickness of intermediate stiffener ST (Fig. 10b and Table 5) was gradually changed in such a way so that the effect of relative flexural stiffness of intermediate stiffeners $\gamma$ on the location of the failure zone in the corrugated web could be found. The length of the span $a$ remained identical for all numerical models. The intermediate stiffener constructed from 10, 15 and $20 \mathrm{~mm}$ sheets was employed.

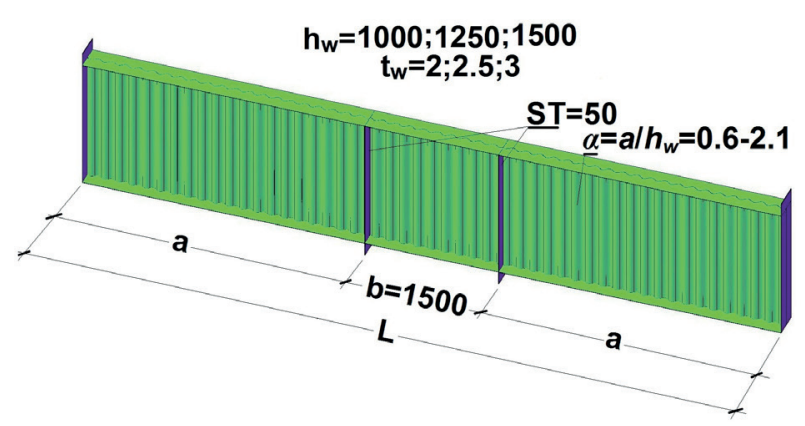

a)

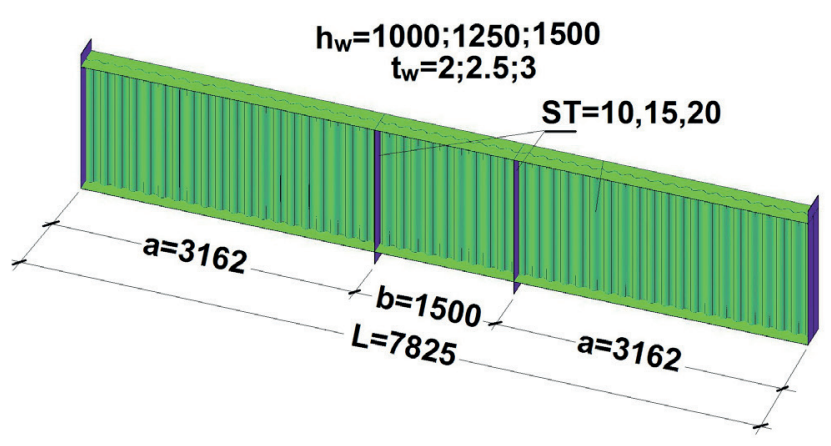

b)

Fig. 10 Numerical models: a) I group; b) II group 
For experimental girders, accurate measurements of the web geometry were taken in the materials tests [23]. In accordance with the measurements, the web shape corresponded to the sine curve. Slight differences were found in the web thickness, the nominal value of which was 2.5 $\mathrm{mm}$. The webs of experimental girders had the thickness of $2 \mathrm{~mm}, 2.5 \mathrm{~mm}$ and $2.6 \mathrm{~mm}$. Additionally, the measurements of chords, intermediate and support stiffeners were taken. It should be noted that in SIN girder manufacture, the automation of sheet metal cutting, chord welding to the web and support stiffeners welding significantly reduces the occurrence of geometric imperfections in the transverse and longitudinal cross sections of fabricated girders. Additionally, measurements of girder rectilinearity were taken and the curvature of girders was checked. Girders did not show geometric imperfections in transverse or longitudinal cross-sections.

The fact above was of cardinal importance because geometric imperfections can significantly affect the values of the limit load, buckling load, displacements and also failure modes. Girders were secured against rotation in order to reduce the effect of the LTB on the web failure mode. Following the literature recommendations [11], the web thickness reduction by $10 \%$ of the original value was assumed as a geometric imperfection in the model validation.

Corrugated web was modelled as a sinusoid in the CAD environment. Then, it was transferred to the Abaqus programme, where the ultimate web shape of a given height and length was created. Chords, stiffeners and the corrugated web were modelled using S4R (a 4-node doubly curved shell with reduced integration, having six degrees of freedom at each node, three translations and three rotations) and S3 shell elements. Altogether, the number of finite elements ranged from 32029 (model $h_{w}=1000 \mathrm{~mm} L=2740$ for $\left.\alpha=a / h_{w}=0.6 / 1=0.6\right)$ to $93543\left(\operatorname{model} h_{w}=1500 \mathrm{~mm}\right.$ $L=7825$ for $\left.\alpha=a / h_{w}=3.1 / 1.5=2.1\right)$.

Table 5 Numerical program of the model of group I

\begin{tabular}{lccccc}
\hline $\begin{array}{l}\text { Web } \\
h_{w} \times t_{w} \\
{[\mathrm{~mm}]}\end{array}$ & $\begin{array}{c}\text { Flange } \\
{[\mathrm{mm}]}\end{array}$ & $\begin{array}{c}\text { Inter- } \\
\text { mediate } \\
\text { stiffener } \\
{[\mathrm{mm}]}\end{array}$ & $\alpha=a / h_{w}$ & $\begin{array}{c}b \\
{[\mathrm{~mm}]}\end{array}$ & $\begin{array}{c}\text { Number } \\
\text { of } \\
\text { models }\end{array}$ \\
\hline $\begin{array}{l}1000 \times \\
2 ; 2.5 ; 3\end{array}$ & $300 \times 15$ & $300 \times 50$ & $0.6,1.0,1.5,2.1$ & 1500 & 12 \\
$1250 \times$ & $300 \times 15$ & $300 \times 50$ & $0.6,1.0,1.5,2.1$ & 1500 & 12 \\
$2 ; 2.5 ; 3$ & & & & & \\
$1500 \times$ & $300 \times 15$ & $300 \times 50$ & $0.6,1.0,1.5,2.1$ & 1500 & 12 \\
$2 ; 2.5 ; 3$ & & & & & \\
\hline
\end{tabular}

\subsection{Type of numerical analysis}

In the numerical analysis applied to the models, the Riks method was used. In this method, the load is applied proportionally in successive load steps, and the so-called path parameter is the control parameter. The method allows finding a solution to the problem regardless of the web buckling mode. That involves identifying load-displacement equilibrium at the end of each iterative step. While seeking load-displacement equilibrium, load can be increased or decreased until limit resistance is reached acc. [24]. This method is one of the best tools for non-linear analysis, therefore it is very often used in buckling analysis.

\subsection{Load and boundary conditions}

Boundary conditions adopted for numerical models (Fig. 10) were the same as for experimental girders (Fig. 3). On the left support, the possibility of vertical $\left(U_{z}=0\right)$, longitudinal $\left(U_{x}=0\right)$ and sideways $\left(U_{y}=0\right)$ displacements was excluded. As regards the right support, the possibility of vertical $\left(U_{z}=0\right)$ and sideways $\left(U_{y}=0\right)$ displacements was eliminated. At the site of the location of intermediate stiffeners, numerical models were secured against lateral torsional buckling (LTB), which means the possibility of longitudinal displacements $\left(U_{y}=0\right)$, and girder rotation around axis $\mathrm{x}\left(\phi_{x}=0\right)$ were ruled out. Additionally, the support conditions of experimental girders included the following: on the left side, the girders rested on hinge support, and on the right side - on the roller support in the form of a bearing.

Longitudinal load (Fig. 11) was applied to intermediate stiffeners of the models as a pair of concentrated forces $2 \times P / 2$. At the site of load application, additional $20 \mathrm{~mm}$ separator sheets were employed. This was the representation of how the load was transferred in the experiment. The load step was linear until the instant of the occurrence of the web stability failure. Then, the load step became non-linear until the limit resistance was reached. The exceedance of the limit resistance was followed by the unloading of the numerical model.

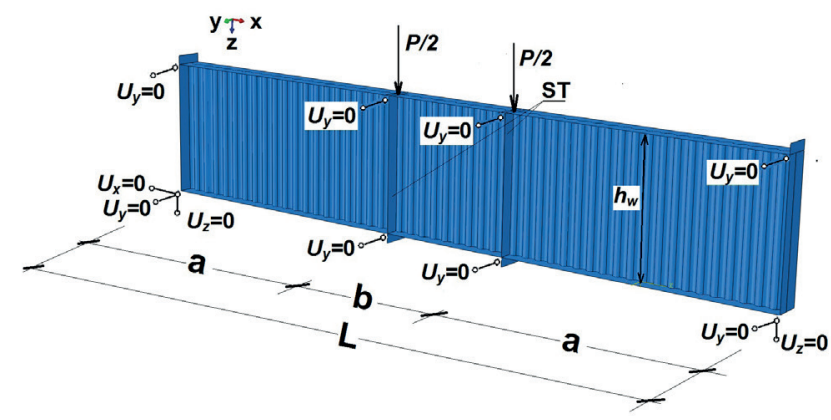

Fig. 11 Boundary conditions and load application to girder 
Table 6 Numerical program of the model of group II

\begin{tabular}{lcccccc}
\hline $\begin{array}{l}\text { Web } \\
h_{w} \times t_{w} \\
{[\mathrm{~mm}]}\end{array}$ & $\begin{array}{c}\text { Flange } \\
{[\mathrm{mm}]}\end{array}$ & $\begin{array}{c}\text { Inter- } \\
\text { mediate } \\
\text { stiffener } \\
{[\mathrm{mm}]}\end{array}$ & $\begin{array}{c}a \\
{[\mathrm{~mm}]}\end{array}$ & $\begin{array}{c}b \\
{[\mathrm{~mm}]}\end{array}$ & $\begin{array}{c}L \\
{[\mathrm{~mm}]}\end{array}$ & $\begin{array}{c}\text { Number } \\
\text { of } \\
\text { models }\end{array}$ \\
\hline $\begin{array}{l}1000 \times \\
2 ; 2.5 ; 3\end{array}$ & $300 \times 15$ & $300 \times 10$ & 3162 & 1500 & 7825 & 3 \\
$1250 \times$ & $300 \times 15$ & $300 \times 10$ & 3162 & 1500 & 7825 & 3 \\
$2 ; 2.5 ; 3$ & & & & & & \\
$1250 \times$ & $300 \times 15$ & $300 \times 15$ & 3162 & 1500 & 7825 & 3 \\
$2 ; 2.5 ; 3$ & & & & & & 3 \\
$1500 \times$ & $300 \times 15$ & $300 \times 10$ & 3162 & 1500 & 7825 & 3 \\
$2 ; 2.5 ; 3$ & & & & & & \\
$1500 \times$ & $300 \times 15$ & $300 \times 15$ & 3162 & 1500 & 7825 & 3 \\
$2 ; 2.5 ; 3$ & & & & & & \\
$1500 \times 3$ & $300 \times 15$ & $300 \times 20$ & 3162 & 1500 & 7825 & 1 \\
\hline
\end{tabular}

4.3 Load - displacements paths of numerical models $\boldsymbol{P ( y )}$ The first stage of the numerical validation involved a 'perfect' model, in which no imperfections were accounted for. The ratio of the FEM limit load to that from the tests $P_{\text {URdINV }} / P_{\text {URdFEM }}$ was $9 \%$. The next stage of validation was conducted using the 'imperfect' model. The initial imperfection consisted in the thinning of the web by $1 / 10$ of its thickness acc. [11]. The dimensions of the web, stiffeners and chords were mapped based on the measurements. The materials model was that produced from materials tests on the properties of the steel used in experimental girders. The model accounted for Huber-Mises-Hencky yield criterion acc. EC3 [14].

The comparison of girders M $1.21(1000 \times 2.5)$ and the 'imperfect' numerical model $1000 \times 2.5$ (similar results from materials tests with respect to yield strength [23]) shows that the estimates of limit load $P_{u R d}$ obtained through FEM analysis are congruent with the results of experimental tests (cf. Table 2 and Table 6). As for buckling load $P_{e B}$, compared with the experimental tests, the difference was $15 \%$. The difference resulted from slight skidding of the roller bearing used as a roller support. The roller bearing skidding contributed to increased displacements $y$ and reduced actual buckling load in experimental girders. The manner of support also made it necessary to adjust load to displacement. As a result, the character of each of the experimental LDPs $P(y)$ was slightly different. In the FEM analysis, the models were supported on the end stiffener, as it is usually done in actual structures. The initial shift was avoided and higher values of the buckling load, closer to the actual ones, were obtained. Additionally, slightly different shapes of curves $P(y)$ were observed. The buckling load from LDPs $P(y)$ was correlated to the method of the control of the length of the arc. For the remaining numerical models, the values of the buckling load and limit load turned out to be different because of different yield strength values.

Based on global displacement $y$ and load $P$, load displacement paths LDPs $P(y)$ were obtained for all analysed numerical models of two girder groups. The analysis of LDPs $P(y)$ provided the coordinates of characteristic points $P_{1}\left(P_{e B}\right)$ and $P_{2}\left(P_{u R d}\right)$ that refer to the resistance of numerical models.

Figs. 12a and $12 \mathrm{~b}$ show exemplary paths LDPs $\mathrm{P}(\mathrm{y})$ of numerical models of girders $1500 \times 2$ with intermediate stiffeners ST, $50 \mathrm{~mm}$ and $10 \mathrm{~mm}$ in thickness, for the parameter value $\alpha=2.1$. The boundary between rectilinear and nonlinear portions of global displacement $y$ was assumed to be the point of the web stability failure $P_{1}\left(P_{e B}\right)$.

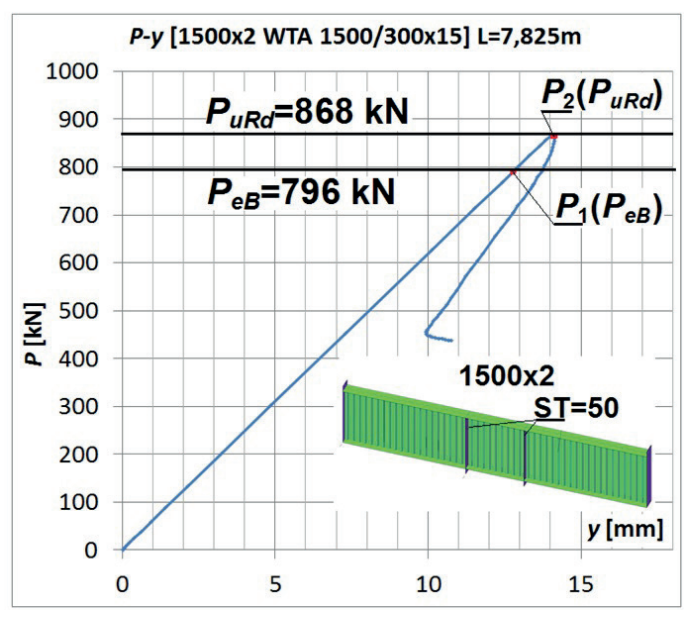

a)

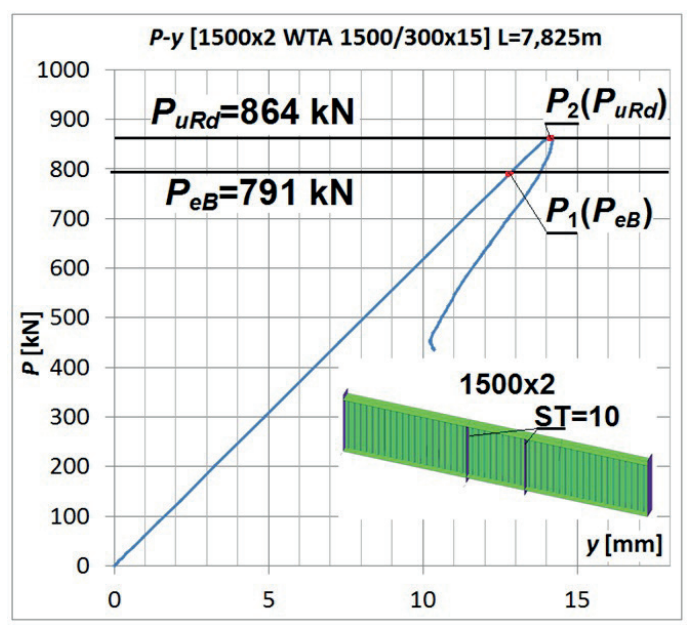

b)

Fig. 12 Comparison of LDPs $P(y)$ : a) FEM $1500 \times 2(300 \times 50 \mathrm{~mm}, \alpha=2.1)$, b) FEM $1500 \times 2(300 \times 10 \mathrm{~mm}, \alpha=2.1)$; 
Table 7 Numerical results for group I of the models (The Riks method)

\begin{tabular}{|c|c|c|c|c|c|c|c|c|c|}
\hline \multirow[t]{2}{*}{$\begin{array}{l}\text { Girder } \\
h_{w} \times t_{w} \\
{[\mathrm{~mm}]}\end{array}$} & \multirow[t]{2}{*}{$\begin{array}{l}\text { Inter-mediate } \\
\text { stiffener } \\
{[\mathrm{mm}]}\end{array}$} & \multicolumn{4}{|c|}{$\begin{array}{l}\text { First buckling load } \\
\qquad \begin{array}{c}P_{e B}[\mathrm{kN}] \\
\alpha=a / h_{w}\end{array}\end{array}$} & \multicolumn{4}{|c|}{$\begin{array}{l}\text { Limit load } \\
P_{u R d}[\mathrm{kN}] \\
\alpha=a / h_{w}\end{array}$} \\
\hline & & 0.6 & 1.0 & 1.5 & 2.1 & 0.6 & 1.0 & 1.5 & 2.1 \\
\hline $1000 \times 2$ & $300 \times 50$ & 550.8 & 530.0 & 528.0 & 527.2 & 584.1 & 582.1 & 579.1 & 579.6 \\
\hline $1000 \times 2.5$ & $300 \times 50$ & 689.5 & 668.0 & 661.5 & 660.0 & 729.1 & 727.1 & 726.5 & 726.3 \\
\hline $1000 \times 3$ & $300 \times 50$ & 828.6 & 804.6 & 795.0 & 791.8 & 876.1 & 875.5 & 874.1 & 872.2 \\
\hline $1250 \times 2$ & $300 \times 50$ & 688.5 & 664.0 & 660.1 & 660.0 & 729.1 & 727.9 & 725.7 & 723.0 \\
\hline $1250 \times 2.5$ & $300 \times 50$ & 861.3 & 834.4 & 829.9 & 825.0 & 912.1 & 909.1 & 907.8 & 906.0 \\
\hline $1250 \times 3$ & $300 \times 50$ & 1035.0 & 1003.5 & 995.7 & 990.8 & 1095.2 & 1093.2 & 1089.7 & 1089.1 \\
\hline $1500 \times 2$ & $300 \times 50$ & 816.6 & 793.8 & 790.7 & 796.2 & 877.0 & 871.1 & 870.4 & 867.9 \\
\hline $1500 \times 2.5$ & $300 \times 50$ & 1026.0 & 993.0 & 976.0 & 989.6 & 1095.9 & 1090.3 & 1088.3 & 1085.9 \\
\hline $1500 \times 3$ & $300 \times 50$ & 1239.3 & 1202.4 & 1179.9 & 1185.5 & 1314.2 & 1310.4 & 1306.4 & 1303.9 \\
\hline
\end{tabular}

Table 8 Numerical results of group II of the models (The Riks method)

\begin{tabular}{lcccc}
\hline $\begin{array}{l}\text { Girder } \\
h_{w} \times t_{w} \\
{[\mathrm{~mm}]}\end{array}$ & $\begin{array}{c}\text { Inter- } \\
\text { mediate } \\
\text { stiffener } \\
{[\mathrm{mm}]}\end{array}$ & $\alpha=a / h_{w}$ & $\begin{array}{c}\text { First } \\
\text { buckling load } \\
P_{e B} \\
{[\mathrm{kN}]}\end{array}$ & $\begin{array}{c}\text { Limit load } \\
P_{u R d} \\
{[\mathrm{kN}]}\end{array}$ \\
\hline $1000 \times 2$ & $300 \times 10$ & 3.1 & 527.0 & 577.9 \\
$1000 \times 2.5$ & $300 \times 10$ & 3.1 & 659.6 & 724.5 \\
$1000 \times 3$ & $300 \times 10$ & 3.1 & 791.2 & 870.2 \\
$1250 \times 2$ & $300 \times 10$ & 2.5 & 659.5 & 720.9 \\
$1250 \times 2.5$ & $300 \times 10$ & 2.5 & 823.2 & 904.2 \\
$1250 \times 3$ & $300 \times 10$ & 2.5 & 987.7 & 1083.2 \\
$1250 \times 2$ & $300 \times 15$ & 2.5 & 659.9 & 722.8 \\
$1250 \times 2.5$ & $300 \times 15$ & 2.5 & 823.6 & 904.8 \\
$1250 \times 3$ & $300 \times 15$ & 2.5 & 988.2 & 1084.8 \\
$1500 \times 2$ & $300 \times 10$ & 2.1 & 795.8 & 864.0 \\
$1500 \times 2.5$ & $300 \times 10$ & 2.1 & 988.4 & 1081.8 \\
$1500 \times 3$ & $300 \times 10$ & 2.1 & 1183.7 & 1300.4 \\
$1500 \times 2$ & $300 \times 15$ & 2.1 & 796.1 & 868.2 \\
$1500 \times 2.5$ & $300 \times 15$ & 2.1 & 989.4 & 1085.6 \\
$1500 \times 3$ & $300 \times 15$ & 2.1 & 1185.1 & 1302.3 \\
$1500 \times 3$ & $300 \times 20$ & 2.1 & 1185.3 & 1303.3 \\
\hline & & & &
\end{tabular}

The paths LDPs $P(y)$ turned out to be similar. However, they slightly differ in character due smaller global displacement $y$ obtained from FEM analysis. Both for experimental and numerical girders, the instability of the corrugated web occurred at point $P_{1}\left(P_{e B}\right)$. That was followed by curvilinear pattern of paths that ended at the boundary point $P_{2}\left(P_{u R d}\right)$. In numerical models, by contrast, the range of postbuckling resistance was significantly shorter.

On the basis of the estimation of the buckling load at point $P_{1}\left(P_{e B}\right)$, shear buckling strength was determined. The latter was employed to determine stiffness criterion for intermediate stiffeners, which depends on the magnitude of the plate geometry parameter $\alpha$. Also, shear buckling strength made it possible to examine the effect of relative flexural stiffness of intermediate stiffeners $\gamma$ on the location of the failure zone of the corrugated web.

Tables 7 and 8 summarise the resistance, estimated on the basis of FEM analysis, of numerical models from both groups. Buckling load $P_{e B}$ and limit load $P_{u R d}$ measured by force $P$ were given.

\subsection{Failure modes in numerical models of girders}

A further validation stage involved a comparison of failure modes in numerical and experimental models. Fig. 13 shows failure modes that occur when $50 \mathrm{~mm}$ thick intermediate stiffeners and semirigid stiffeners located at the end of the girder are used. With $50 \mathrm{~mm}$ thick intermediate stiffeners, the failure of the web of the numerical models and experimental girders occurred in the support area at 1900 to $2200 \mathrm{~mm}$ distance from the intermediate stiffener. However, intermediate stiffeners remained intact. Modes of girder failure obtained from the experiment and FEM analysis turned out to be very close to each other (Fig. 13 $a$ and $b$, and also Fig. 7). The effect of the span length a for $a<h_{w}$ at a constant thickness of the intermediate stiffener produced only a small increase in the buckling load.

In all numerical models, regardless of the intermediate stiffener thickness, after the formation of tension lines (1), tension field led to the yield zone formation and opposite buckling of the web waves (interactive stability failure - I) $[25,26]$. Next, the yield of flanges in the girder plane occurred (Fig. 13).

In girders with thinned intermediate stiffener, the web failure zone was shifted towards intermediate stiffener (Fig. 14). Reduction in the stiffener thickness caused a 


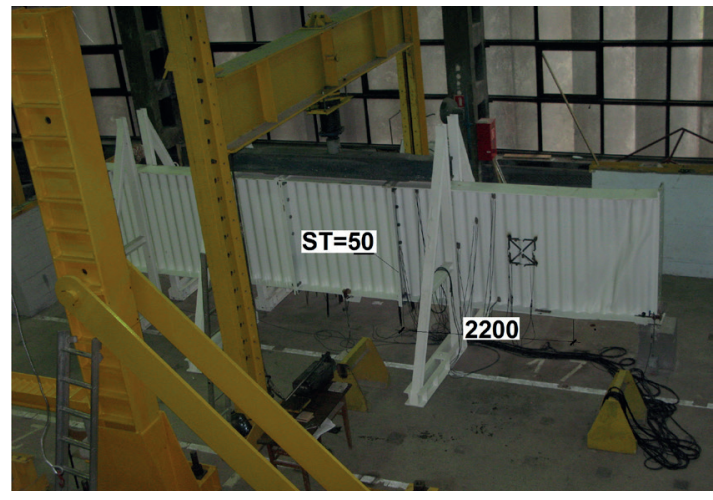

a)

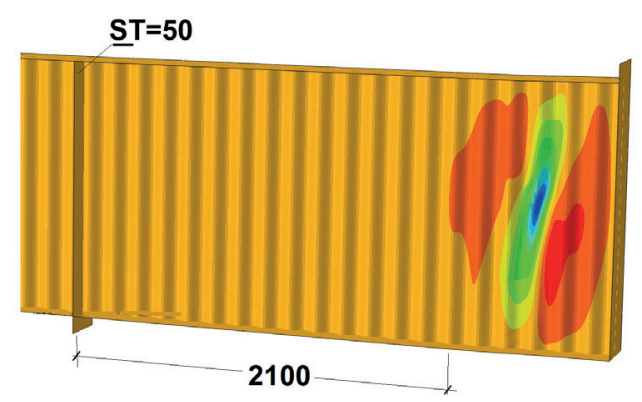

b)

Fig. 13 Comparison of failure modes: a) experimental girder M $1.51(1500 \times 2$ : stiffener $300 \times 50 \alpha=2.1)$, b) numerical model $1500 \times 2$ (stiffener: $300 \times 50 \alpha=2.1)$

change in the ratio of stiffener to web stiffness $E I_{s} / E I_{w}$, which led to free deformation of the web. Fig. 14a shows a numerical girder model $1250 \times 3$ with $10 \mathrm{~mm}$ thick intermediate stiffener that satisfies the stiffness criterion. However, its absolute stiffness $I_{s}$ does not make it possible to change the failure site location. Only when the stiffness of the stiffener is increased to above $I_{s F}$ (Fig. 14b), the location of the web buckling is altered. Both applied stiffeners satisfy the stiffness criterion, which virtually does not affect shear buckling resistance. Increased stiffness of the stiffener, however, leads to a change in failure location. Fig. 14c illustrates the web failure of $1500 \times 3$ girder with a stiffener, the stiffness of which is only slightly greater than the minimum stiffness $I_{s}$. The use of the stiffener with stiffness lower than the minimum one results in the stiffener buckling. After the immediate stiffener has buckled, because of small web thickness, in the first stage, the web failure occurs induced by the pressure force. The subsequent stage may involve failure in the form of diagonal yield line that propagates over the whole web. In actual structures of corrugated web girders, intermediate stiffeners are applied when large concentrated loads are expected. Then, the absolute stiffness of the stiffener must be greater than the minimum one.

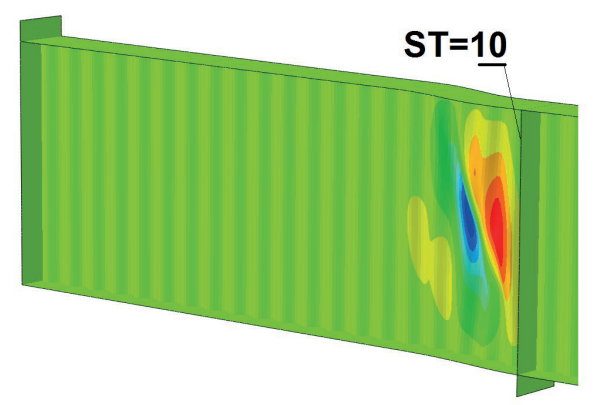

a)

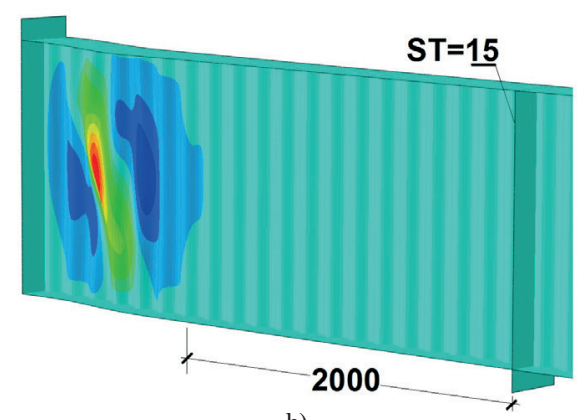

b)

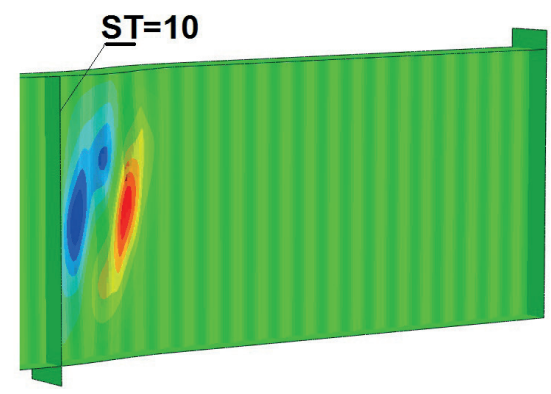

c)

Fig. 14 Comparison of failure modes: a) $1250 \times 3(300 \times 10 \alpha=2.1)$, b) $1250 \times 3(300 \times 15 \alpha=2.1)$, c) $1500 \times 3(300 \times 15 \alpha=2.1)$

\section{Stiffness criterion for intermediate stiffeners}

To estimate relative flexural stiffness $\gamma$ of the intermediate stiffener, shear buckling resistance $\tau_{c r, B}$ was determined from dependence Eq. (9). That was done using FEM analysis of numerical models of girder group I at point $P_{1}\left(P_{e B}\right)$ related to the onset of the web stability failure:

$\tau_{c r, B}=0.5 P_{e B} / h_{w} t_{w}$,

where: $P_{e B}-$ the first buckling load.

Optimum stiffness $\gamma$ of the intermediate stiffener was estimated on the basis of the ratio of buckling resistance $\tau_{c r, B}$ to Euler critical stress $\tau_{e}$. However, optimal stiffness $\gamma$ of the intermediate stiffener described by Eq. (10) depends on Young modulus, height of the corrugated web and flexural stiffness of the corrugated web plate Eq. (11).

$\gamma=\frac{E I_{s}}{D h_{w}}$ 
$D=\frac{E t_{w}^{3}}{12\left(1-v^{2}\right)} \frac{w}{s}$

where $w=77.5 \mathrm{~mm}$ denotes the length of the chord of the half-sine wave, $s=89 \mathrm{~mm}$ - length of the arc of half-sine wave, $v=0.3-$ Poisson's ratio, $h_{w}, t_{w}-$ web height and thickness.

When the optimum stiffness of the stiffener Eq. (10) is combined with the plate stiffness of the corrugated web Eq. (11), the resultant expression describes the minimum absolute stiffness of the stiffener $I_{\text {smin }}$, namely:

$I_{\text {smin }}=k_{s} h_{w} t_{w}^{3}$,

where: $k_{s}$ denotes dimensionless stiffness coefficient of the stiffener, dependent on the stiffener optimum stiffness $\gamma$.

$k_{s}=\frac{\gamma}{10.92} \frac{w}{s}$

The Eq. (12) was based on formulas acc. EC 3 [14]. Additionally, a dimensionless coefficient of the stiffness of the stiffener $k_{s}$ was introduced.

The results obtained for the dimensionless stiffness coefficient $k_{s}$ of the stiffener, dependent on the geometry parameter $\alpha$, for individual numerical models of girder group I are listed in Table 9.

The empirical formula $k_{s}(\alpha)$ was smoothed using a non-linear regression curve Eq. (14). Coefficients of the power function that were different from zero were calculated using the least square method.

$k_{s}(\alpha)=a \alpha^{b}+c$,

Table 9 Dimensionless coefficient of stiffness of the intermediate stiffener

\begin{tabular}{lccccc}
\hline $\begin{array}{l}\text { Girder } \\
h_{w} \times t_{w} \\
{[\mathrm{~mm}]}\end{array}$ & $\begin{array}{c}\text { Inter. } \\
\text { stiffener } \\
{[\mathrm{mm}]}\end{array}$ & \multicolumn{5}{c}{$\alpha=a / h_{w}$} \\
\hline & & 0.6 & 1.0 & 1.5 & 2.1 \\
$1000 \times 2$ & $300 \times 50$ & 14.90 & 14.34 & 14.28 & 14.26 \\
$1000 \times 2.5$ & $300 \times 50$ & 9.55 & 9.25 & 9.16 & 9.14 \\
$1000 \times 3$ & $300 \times 50$ & 6.64 & 6.45 & 6.37 & 6.35 \\
$1250 \times 2$ & $300 \times 50$ & 23.28 & 22.45 & 22.32 & 22.32 \\
$1250 \times 2.5$ & $300 \times 50$ & 14.91 & 14.45 & 14.37 & 14.28 \\
$1250 \times 3$ & $300 \times 50$ & 10.37 & 10.05 & 9.98 & 9.93 \\
$1500 \times 2$ & $300 \times 50$ & 32.26 & 32.21 & 32.09 & 32.31 \\
$1500 \times 2.5$ & $300 \times 50$ & 20.66 & 20.63 & 20.27 & 20.55 \\
$1500 \times 3$ & $300 \times 50$ & 14.36 & 14.35 & 14.19 & 14.25 \\
\hline
\end{tabular}

Table 10 Curves $k(\alpha)$ acc. Eq. (15) obtained by means of regression

\begin{tabular}{lcc}
\hline $\begin{array}{l}\text { Girder } \\
h_{w} \times t_{w} \\
{[\mathrm{~mm}]}\end{array}$ & $\begin{array}{c}\text { Inter. } \\
\text { stiffener } \\
{[\mathrm{mm}]}\end{array}$ & $k_{s}(\alpha)$ \\
\hline $1000 \times 2$ & $300 \times 50$ & $k_{s}(\alpha)=0.076 \alpha^{-4.163}+14.263$ \\
$1000 \times 2.5$ & $300 \times 50$ & $k_{s}(\alpha)=79566.471 \alpha^{0.0000025}-79557.239$ \\
$1000 \times 3$ & $300 \times 50$ & $k_{s}(\alpha)=0.006 \alpha^{-2.446}+6.342$ \\
$1250 \times 2$ & $300 \times 50$ & $k_{s}(\alpha)=0.151 \alpha^{-3.663}+22.297$ \\
$1250 \times 2.5$ & $300 \times 50$ & $k_{s}(\alpha)=1.121 \cdot 10^{5} \alpha^{0.0000026}-1.121 \cdot 10^{5}$ \\
$1250 \times 3$ & $300 \times 50$ & $k_{s}(\alpha)=0.018 \alpha^{-2.920}+9.900$ \\
$1500 \times 2$ & $300 \times 50$ & $k_{s}(\alpha)=0.007 \alpha^{-9.686}+32.201$ \\
$1500 \times 2.5$ & $300 \times 50$ & $k_{s}(\alpha)=96701.354 \alpha^{0.0000027}-96680.638$ \\
$1500 \times 3$ & $300 \times 50$ & $k_{s}(\alpha)=52872.115 \alpha^{0.0000024}-52857.923$ \\
\hline
\end{tabular}

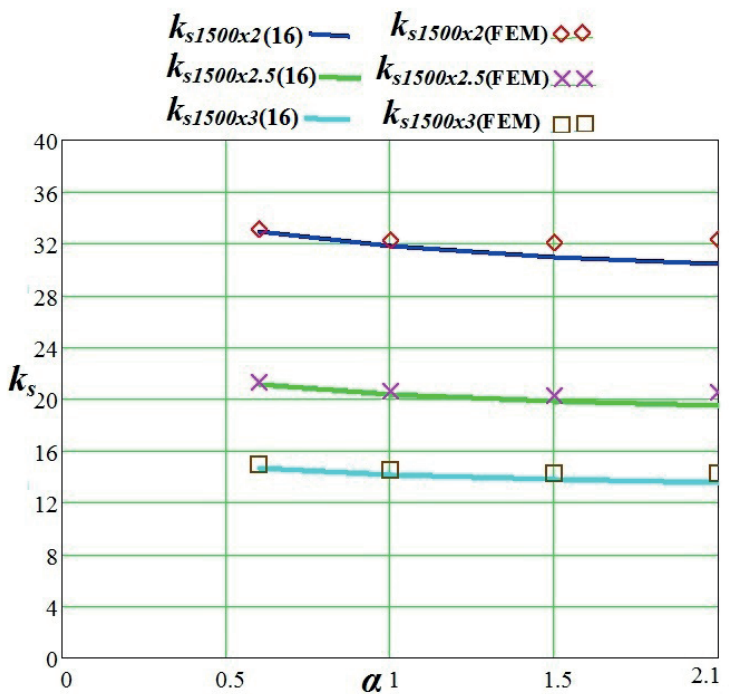

Fig. 15 Dimensional stiffness coefficients of the stiffeners in girders with corrugated web for $h_{w}=1500 \mathrm{~mm}$

In order to regularise the dimensionless stiffness coefficient of stiffeners $k_{s}$, the regression curve Eq. (14) was equalised to the curve Eq. (15).

$k_{s}(\alpha)=a \alpha^{b}+c=a_{1} \alpha^{-1 / 15}$.

The coefficient $a_{1}$ was determined. On the basis of coefficient $a_{1}$, the dimensionless stiffness coefficient of stiffeners $k_{s}$, applicable to all models, was estimated:

$k_{s}=\frac{6.5 \cdot 10^{-5}}{\alpha^{1 / 15}}\left(\frac{h_{w}^{2}}{t_{w}^{2}}\right) \frac{w}{s}$.

Table 10 shows the curves, obtained through numerical analysis, describing the dimensionless stiffness coefficient of stiffeners $k_{s}(\alpha)$, which were smoothed using non-linear regression Eq. (15).

Fig. 15 illustrates the curves of the dimensionless stiffness coefficient of stiffeners $k_{s}(\alpha)$ acc. Eq. (16) for exemplary numerical models of group I girders that had 
$h_{w}=1500 \mathrm{~mm}$ and the web thickness of 2, 2.5 and $3 \mathrm{~mm}$. In the graphs, four measurement points were marked obtained from numerical analysis.

Thus, the minimum stiffness of the stiffener Ismin in girders with corrugated web can be expressed by Eq. (17):

$$
I_{s \min }=\frac{6.5 \cdot 10^{-5}}{\alpha^{1 / 15}} h_{w}^{3} t_{w} \frac{w}{s} .
$$

In addition, increased absolute stiffness of intermediate stiffeners leads to a change in the location of the corrugated web buckling. Coefficients $\eta F$ that allow obtaining appropriate stiffness of intermediate stiffeners $I_{s F}$ were adopted on the basis of numerical analysis of group II models. When properly selected, the stiffness of intermediate stiffeners results in the shift of the failure zone to the girder support zone. For girders with the web height of $h_{w}=1000,1250$ and $1500 \mathrm{~mm}$, the values of coefficients are $\eta F=200,110$ and 90 , respectively. As a result, the minimal stiffness of the stiffener $I_{s F}$ that causes the failure zone shift to the support zone of the corrugated web girder is as follows:

$I_{s F}=\eta_{F} k_{s} h_{w} t_{w}^{3}=\eta_{F} \frac{6.5 \cdot 10^{-5}}{\alpha^{1 / 15}} h_{w}^{3} t_{w} \frac{w}{s}$.

For intermediate stiffener with stiffness $I_{\text {smin }}<I_{s}<I_{s F}$, the web failure occurs near the stiffener (Fig. 16a). It is possible to increase the stiffness of the immediate stiffener to above $I_{s F}$, so that the failure zone could be transferred to the support area (Fig. 16b). This area can be secured with, e.g. tension diagonal braces, and the overall girder bearing capacity can be enhanced [27].

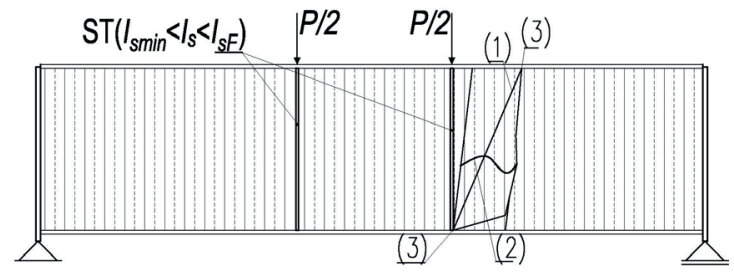

a)

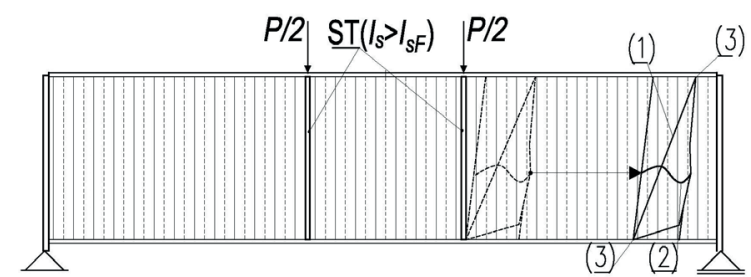

b)

Fig. 16 Influence of the stiffness of the intermediate stiffener on the location of the zone of failure of the corrugated web: a) stiffener $I_{\text {smin }}<I_{s}<I_{s F}$; b) stiffener $I_{s}>I_{s F}$

\section{Results and evaluations of adopted solution}

Both experimental girders and numerical models failed in the area under the constant action of shear force. The failure was caused by interactive (I) mode of the corrugated web stability failure. In girders with intermediate stiffener, the stiffness of which was $I_{s}>I_{s F}$, the web failure zone was shifted to the girder support zone. Due to the fact that dimensionless stiffness coefficients $k_{s}$ for corrugated web girders are not available in the literature, the obtained values of the coefficient were compared with those for flat web girders. Dimensionless coefficients of flexural stiffness of intermediate stiffener $k_{s}$ are dependent on geometry parameter $\alpha$. They were shown for the solution acc. EC3 [14] $\left(k_{s E C 3}\right)$, and those presented by Moore $\left(k_{s M}\right)$, Klöppel and Scheer $\left(k_{S K S}\right)$, and for the solution devised by the author with respect to corrugated webs $\left(k_{s 1500}\right)$ (Table 10). The graphs are depicted in Fig. 17.

On the basis of the analysis of the graphs (Fig. 17) of dimensionless stiffness coefficients $k_{s}$ for flat web girders, it can be seen that those obtained acc. EC3 and Moore's proposal are functions that decrease monotonically towards the asymptote. This line is determined by the constant value of coefficient $k_{s}$ for panels, the parameter $\alpha$ value of which is $\alpha>\sqrt{2}$. The characteristics of coefficient $k_{s}$ in accordance with the proposal by Klöppel and Scheer $\left(k_{s K S}\right)$ are slightly different at the initial stage when $\alpha<0.5$. It should be noted for flat webs at $\alpha>\sqrt{2}$, the effect of stiffener on increase in buckling stress is reduced. That justifies the adoption of the constant value of coefficient $k_{s}$ for elongated web panels.

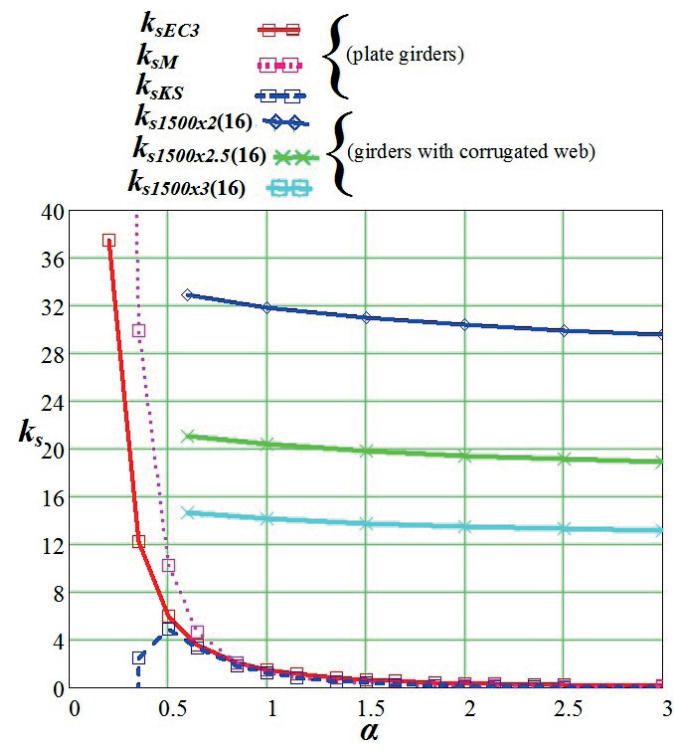

Fig. 17 Comparison of dimensionless flexural stiffness coefficients of stiffeners $k_{s}$ acc. EC3, Moore, Klöppel - Scheer, and the experiment 
As regards girders with corrugated web, the graphs of dimensionless stiffness coefficients $k_{s}$ also represent functions of the web plate geometry parameter $\alpha$ that decrease monotonically towards the determined asymptote. For corrugated web girders, however, intermediate stiffeners have low influence on buckling stress. Due to that reason, the range of variation in stiffness coefficient $k_{s}$ is incomparably small, and it virtually disappears when the value is $\alpha>1.0$. However, values of stiffness coefficient $k_{s}$ for corrugated web girders are higher due to increased buckling stress obtained in the stiffened plate of the corrugated web.

\section{Conclusions}

SIN-type corrugated web girders are internally statically indeterminate systems. Dimensions of stiffeners and flanges interact and affect the design shear buckling resistance. The loss of shear resistance in girders with corrugated web is related to the occurrence of tension lines along yield zones in the corrugated web. Yield zones are irreversible and largely responsible for reduction in the girder resistance.

In corrugated web girders, intermediate stiffeners are used as components of girder connection to secondary beams, protection against pressing force, or end-plate connections in pre-assembled elements.

The use of intermediate stiffeners in girders with corrugated web with stiffness greater than $I_{\text {smin }}$ does not produce a significant increment of buckling stress in the web. Consequently, the range of variation in buckling stress and stiffness coefficient $k_{s}$ virtually fades away when the value of the plate geometry parameter is $\alpha>1.0$.

\section{References}

[1] Timoshenko, S. P. "Historia wytrzymałości materiałów" (History of strength of materials), 2nd ed., Arkady, Warsaw, Poland, 1966. (in Polish)

[2] Timoshenko, S. P., Gere, J. M. "Teoria stateczności sprężystej" (The theory of elastic stability), 2nd ed., Arkady, Warsaw, Poland 1961. (in Polish)

[3] Moore, R. L. "An Investigation on the effectiveness of stiffeners on shear-resistance plate-girder webs", Rep. NACA-TN-862, National Advisory Committee for Aeronautics, Washington, USA, 1942. [online] Available at: http://hdl.handle.net/2060/19930081613 [Accesed:23.04.2019]

[4] Rockey, K. C. "The design of intermediate vertical stiffeners on web plates subjected to shear", The Aeronautical Quarterly, 7(4), pp. 275-296, 1956.

https://doi.org/10.1017/S0001925900010295

[5] Klöppel, K., Scheer, J. "Beulwerte ausgesteifter Rechteckplatten" (Buckling stiffened rectangular plates), 1st ed., Verlag von Wilhelm Ernst \& Sohn, Berlin, Germany, 1960. (in German)
Minimum stiffness of the intermediate stiffener in corrugated web girders $I_{\text {smin }}$ is satisfied for stiffeners acc. the proposed stiffness criterion expressed by Eq. (17).

Conversely, the stiffness of the intermediate stiffener in corrugated web girders, expressed by Eq. (18), should be greater than stiffness $I_{s F^{*}}$. That ensures sufficient stiffening of the web and flanges at the site where concentrated load is applied, and guarantees a change in the shear buckling location.

In girders with corrugated web, intermediate stiffeners should be used to shift the failure zone of the corrugated web to the support. Intermediate stiffeners can be employed to control the location of the yield zone lines. Thus, they make it possible to evaluate the condition of the critical sites of the girder web.

Eqs. (17) and (18) describe well framed girder webs and they can be applied to the whole range of products with the height ranging from 500 to $1500 \mathrm{~mm}$.

At the present state of research into instability of webs in SIN girders, it is propounded that structural members with stiffness $I_{s F}$ should be used as intermediate stiffeners at the site where concentrated loads are applied. Also, rigid support stiffeners should be employed, and torsional stiffness of chords should be increased. Then, to adjust flexural and shear resistance in corrugated web girders, it is possible to use tension diagonals in the girder support zones [27], in which shear load occurs that is greater than the web shear resistance.

\section{Acknowledgements}

The research is financed by National Science Centre based on grant No. N N506 072538.

[6] Galambos, T. V. "Guide to stability design criteria for metal", 4th ed., Wiley, New York, USA, 1988.

[7] Maqoui, R., Massonnet, Ch., Škaloud, M. "Design of stiffened webs", Stavebnícky Časopis, 2, pp. 73-88, 1981.

[8] Škaloud, M. "Optimum Rigidity of Stiffeners of Web and Flanges", In: Narayanan, R. (ed.) Plated Structures, Stability and Strength, CRC Press, London, United Kingdom, 1983, pp. 103-134.

[9] Höglund, T. "Shear buckling resistance of steel and aluminium plate girders", Thin-Walled Structures, 29(1-4), pp. 13-30, 1997. https://doi.org/10.1016/S0263-8231(97)00012-8

[10] Basiński, W. "Shear buckling of plate girders with corrugated web restrained by end stiffeners", Periodica Polytechnica Civil Engineering, 62(3), pp. 757-771, 2018. https://doi.org/10.3311/PPci.11554

[11] Kuchta, K. "Sztywność i nośność blachownic o falistych środnikach" (Resistance and stiffness of plate girders with corrugated web), Ph.D. thesis, Cracow University of Technology, 2004. (in Polish) 
[12] Kowal, Z. Basiński, W. "O postaciowej nośności dźwigarów z falistym środnikiem" (The shear resistance of girders with corrugated web), Inżynieria i Budownictwo, 64(4), pp. 197-200, 2008. (in Polish)

[13] Kowal, Z., Basiński, W. "Wpływ sztywności blach czołowych na postaciową wytrzymałość krytyczną dźwigarów o falistym środniku" (The influence of the stiffness of end stiffeners on critical shear resistance of corrugated web of girders), Konstrukcje Stalowe, 3, pp. 50-54, 2013. (in Polish)

[14] Eurocode 3 " EN 1993-1-5. 2008 Design of steel structures. Part 1-5: General rules - Plated structural elements", CEN, Brussels, Belgium, 2008.

[15] "Profile $\mathrm{z}$ falistym środnikiem SIN. Zasady wymiarowania" (Profiles of corrugated web of SIN girders. Principles of dimensioning), Cracow University of Technology, 2002. (in Polish)

[16] Basiński, W. "Kształtowanie konstrukcji szkieletowych z dźwigarów o sfałdowanym środniku łączonych doczołowo" (Shaping frameworks girder on the corrugated web joined by end plates), Research project N N506 072538, Silesian University of Technology, Gliwice, Poland, 2013. (in Polish).

[17] This research was supported in part by PL-GRID infrastructure, and also by the WIND grant.

[18] ECCS "European Recommendation for Steel Construction, The Stressed Skin Design of Steel Structures", European Convention for Constructional Steelwork, Brussels, Belgium, 1978.

[19] ASHTO "Standard specifications for highway bridges", 16th ed., American Association of State Highway and Transportation Officials, Washington, D.C., USA, 1996.

[20] Kowal, Z. "Dźwigary blachowe z użebrowaniem pionowym i przekątnym" (Plate girders with vertical and diagonal stiffeners). Zeszyty Naukowe Politechniki Wrocławskiej, 97, Wrocław, Polska, 1964. (in Polish)
[21] Wuwer, W., Zamorowski, J., Swierczyna, S. "Lap joint stiffness according to Eurocode EC3 and experimental investigations results", Archives of Civil and Mechanical Engineering, 12(1), pp. 95-104, 2012.

https://doi.org/10.1016/j.acme.2012.03.017

[22] "BS EN 10002-1 Metallic materials - Tensile testing - Part 1: Method of test at ambient temperature", BSI Standards Publication, London, United Kingdom, 2001.

[23] Basiński, W., Kowal, Z. "Random strength parameters of steel corrugated webs and their influence on the resistance of SIN plate girders", Architecture Civil Engineering, Environment, 11(3), pp. $65-77,2018$. https://doi.org/10.21307/ACEE-2018-039

[24] Memon, B.-A., Su, X.-Z. "Arc-length technique for nonlinear finite element analysis", Journal of Zhejiang University - Science A, 5(5) pp. 618-628, 2004 https://doi.org/10.1631/jzus.2004.0618

[25] Hamilton, R. W. "Behavior of welded girder with corrugated webs", Ph.D. thesis, University of Maine, 1993.

[26] Hassanein, M. F., Kharoob, O. F. "Behavior of bridge girders with corrugated webs: (II) Shear strength and design", Engineering Structures 57, pp. 544-553, 2013. https://doi.org/10.1016/j.engstruct.2013.04.015

[27] Basiński, W., Kowal, Z. "Investigations into the resistance of sin girders reinforced with tensioned diagonal braces", Architecture Civil Engineering, Environment, 10(1), pp. 53-64, 2017. https://doi.org/10.21307/acee-2017-006 